\title{
SURVEY OF ROTAVIRUS SURVEILLANCE, LABORATORY CAPACITY AND DISEASE BURDEN IN THE EASTERN PART OF THE WHO EUROPEAN REgION
}

\author{
C J Williams (christopher.williams@norfolk.nhs.uk)1,2, Jim Gray ${ }^{1}$, R G Pebody ${ }^{1}$, A Lobanov ${ }^{3}$ \\ 1. Health Protection Agency Centre for Infections, London, United Kingdom \\ 2. European Training Programme for Intervention Epidemiology (EPIET), European Centre for Disease Prevention and Control \\ (ECDC), Stockholm, Sweden \\ 3. World Health Organization Regional Office for Europe, Copenhagen, Denmark (former staff member)
}

Following the licensure of two rotavirus vaccines in Europe, we aimed to assess factors, such as surveillance, disease burden and laboratory capacity, which will be relevant for making decisions about rotavirus vaccine introduction in the different countries. We conducted an email-based survey of the national public health bodies in the World Health Organization (WHO) European Region in 2006 and report here the results from the 23 countries in the eastern part of the region. The survey included questions on rotavirus surveillance, laboratory capacity, burden (in children under the age of five years) and intention to introduce rotavirus vaccination. Countries were grouped into the four per-capita income categories defined by the World Bank.

Fourteen of the 23 countries responded to the survey. All except one country reported that less than a quarter of their laboratories had rotavirus diagnostic capacity. Four countries had some form of specific rotavirus surveillance, but half were of very limited coverage. Ten countries did not report data on the incidence of rotavirus hospital admissions, although nine were able to report some data on rotavirus burden. Six of the responding countries said they were likely to introduce universal rotavirus vaccination.

Rotavirus surveillance and laboratory capacity in the eastern part of the WHO European Region is limited but most countries had some estimate of rotavirus burden, often from special studies. The reported mortality rates were lower than those from a WHO mortality data source. Many countries in the eastern part of WHO European Region face a number of challenges before vaccine implementation, including strengthening surveillance, improving laboratory capacity and addressing financial barriers.

\section{Introduction}

The recent publication of the results of phase III trials of two oral rotavirus vaccines $[1,2]$ showed vaccines that were effective in preventing serious clinical end points of rotavirus infection. The vaccines provide $85-95 \%$ protection against rotavirus infections severe enough to require hospitalisation, and $72-74 \%$ protection against all rotavirus infections [1,2]. However, vaccination appeared to protect only against disease, not to reduce the overall incidence of rotavirus gastrointestinal infection in the target group [2,3]. Following the licensure of both vaccines by the European Medicines Agency (EMEA) $[4,5]$, there has been renewed interest in preventing rotavirus disease in Europe, with many countries considering the introduction of rotavirus vaccine into their routine immunisation schedule.
The introduction of these vaccines will depend upon a number of country-specific factors. These include local disease burden (mortality and morbidity), diagnostic and surveillance capacity, cost of the vaccine (which is relatively expensive [6]), vaccine effectiveness and adverse events profile, as well as competing healthcare priorities.

Rotavirus infections cause a considerable disease burden throughout the world. The burden of rotavirus disease tends to fall predominately on children under the age of five years $[7,8]$, with an estimated half million deaths annually attributable to rotavirus in children under five years mainly in lower income settings [9].

A recent study estimated annual rotavirus disease burden in the (at that time) 25 countries of the European Union at 231 deaths and nearly 90,000 hospital admissions [10]. In the World Health Organization (WHO) European Region, which covers 53 countries, there is some evidence that the burden of acute gastroenteritis (AGE) is higher in some countries in the eastern part of the region $[11,12]$. However, there are fewer published studies of rotavirus disease burden in these areas. The countries without published burden studies may be able to supply burden estimates based on their own surveillance data, or special studies, helping to fill gaps in the burden profile.

Which countries might consider introducing universal childhood rotavirus vaccination? Each country may have different priorities in making such decisions. Higher-income countries may try to reduce primary care consultations, hospitalisations and nosocomial infections by vaccination. Countries with lower incomes and higher AGE mortality rates may find rotavirus vaccination to be life-saving in the under-fives. The GAVI Alliance (Global Alliance for Vaccines and Immunisation) supports rotavirus vaccination initiatives in low-income countries [13].

To provide an overview of the current situation in the eastern part of Europe, we conducted a survey of member states in that part of the WHO European Region. Our objectives were to identify and compare current laboratory capacity and surveillance for rotavirus infection, local disease burden, circulating rotavirus strains and priorities regarding possible vaccine introduction. This comparative information has been shared with the responding countries to assist national decision-making. 


\section{Methods}

We sent, by email, questionnaires in English and Russian to 49 of the 53 countries in the WHO European Region. The surveys to the 23 countries in the eastern part of the region* were sent out from the WHO Regional Office for Europe (WHO/Europe) in Copenhagen, Denmark and the remainder from the Health Protection Agency Centre for Infections in London, United Kingdom (UK). The survey was addressed to the person in the national public health body in each country who was responsible for national rotavirus surveillance. Two email reminders were sent following the return deadline in January 2006.

We found initially that the response rate for surveys sent from the UK was very low (9 of 26; 35\%), and the results suggested that laboratory capacity and data on rotavirus burden was better in the western part than in the eastern part of the WHO European Region. Therefore we present here only the results from the 23 surveys that were sent from the WHO office.

The questionnaire included sections on:

- country-specific details

- laboratory capacity for rotavirus diagnosis

- surveillance systems for gastroenteritis and rotavirus

- reported disease burden (deaths, hospitalisations and primary care consultations due to gastroenteritis and rotavirus)

- and country-specific literature.

It focused on the disease burden in children under the age of five years, as this is the age group most affected by rotavirus $[7,8]$ and the age-range used in comparable literature $[9,10]$. In addition, countries were asked whether they would be likely to introduce rotavirus vaccination in the next five years, and which factors could influence this decision. Survey results were entered directly into a spreadsheet, and data validity was checked against the written surveys before the analysis.
We obtained per capita annual gross national income (World Bank, Atlas method, 2006 data [14]) for each country. For the burden calculations, countries were grouped according to the four income groups (low: below $\$ 905$; lower-middle: $\$ 906$ - \$3,595; upper-middle: $\$ 3,596$ - $\$ 11,115$; high: over $\$ 11,116)$ defined by the World Bank [15].

\section{Results}

\section{Response}

Overall, 14 of 23 (Serbia and Montenegro sent separate returns) questionnaires were returned (61\%). Countries that did not respond were: Armenia, Azerbaijan, Bosnia and Herzegovina, The Former Yugoslav Republic of Macedonia, Kazakhstan, Romania, Russia, Turkmenistan, and Ukraine.

Among the countries that participated in the survey were seven (of 13) low and lower-middle income countries and seven (of 10) upper-middle and high-income countries (see Table 1).

\section{Laboratory capacity}

The median proportion of laboratories with rotavirus testing facilities was $8 \%$ (range $0 \%-100 \%$, Table 1 ). Among the low and lower-middle income countries, Belarus reported that $100 \%$ of the country's laboratories had such facilities, while the other six countries reported diagnostic facilities in fewer than a quarter of their laboratories.

The most common testing methods available were latex agglutination (7/14 countries), enzyme-linked immunosorbent assay (ELISA) (6/14 countries) and polymerase chain reaction (PCR) (4/14 countries). Serology was available in only one, and electron microscopy in only two countries.

\section{Rotavirus surveillance}

Regarding the type of surveillance in place the countries could choose rotavirus-specific surveillance systems, syndromic surveillance for AGE (with or without the quantification of rotavirus infections) or special studies.

T A B L E

Laboratory capacity for rotavirus diagnostics and available methods

\begin{tabular}{|l|l|c|c|l|}
\hline Country & GNI per capita category & $\begin{array}{c}\text { Total laboratories for } \\
\text { stool diagnostics }\end{array}$ & $\begin{array}{c}\text { Percentage of } \\
\text { laboratories with } \\
\text { rotavirus diagnostics }\end{array}$ & Available methods \\
\hline Kyrgyzstan & Low income & 166 & $24 \%$ & ELISA, PCR \\
\hline Tajikistan & Low income & 70 & $0 \%$ & - \\
\hline Uzbekistan & Low income & 60 & $2 \%$ & ELISA \\
\hline Albania & Lower-middle income & 12 & $8 \%$ & ELISA, latex \\
\hline Belarus & Lower-middle income & 11 & $100 \%$ & EM, ELISA, PCR \\
\hline Georgia & Lower-middle income & 62 & - & - \\
\hline Republic of Moldova & Lower-middle income & 50 & $2 \%$ & latex \\
\hline Bulgaria & Upper-middle income & - & - & latex \\
\hline Croatia & Upper-middle income & - & - & - \\
\hline Montenegro & Upper-middle income & - & - & latex \\
\hline Serbia & Upper-middle income & - & $17 \%$ & latex \\
\hline Slovakia & Upper-middle income & 60 & - & - \\
\hline Turkey & Upper-middle income & - & - & EM, ELISA, PCR, latex \\
\hline Slovenia & High income & 8 & - & \\
\hline
\end{tabular}

GNI: Gross national income; EM: Electron microscopy; ELISA: Enzyme-linked immunosorbent assay; PCR: Polymerase chain reaction 
Four of the 14 countries, Kyrgyzstan, Uzbekistan, Belarus and Slovenia, reported having a specific rotavirus surveillance system. In Uzbekistan and Kyrgyzstan the system covered only hospitalised cases (with $0.02 \%$ coverage reported by Kyrgyzstan), whereas in Belarus and Slovenia community cases were also reported by the system.

Nine of the 10 remaining countries reported having syndromic surveillance for gastroenteritis. Two (Moldova and Slovakia) had systems that quantified the contribution of rotavirus to AGE and the remaining seven did not include quantification of rotavirus infections. Turkey did not answer this question.

Only two countries gave a percentage of the population covered by the system (40\% in Albania, and $15 \%$ in Serbia).

\section{AGE burden in children aged under the age of five years (Table 2) Community burden ( $n=13$ responses)}

The median incidence of AGE for community cases was 21.8 per 1,000 children per year (range of 7 to 48 per 1,000 per year). The highest community burden was found in Tajikistan with 48 per 1,000 per year.

\section{Hospitalisation burden ( $n=8$ responses)}

The median incidence of AGE hospital admissions was 18.9 per 1,000 (7.3 to 782 per 1,000) for hospital admissions, but only 9.9 per 1,000 , if the extreme upper-outlier from Albania is excluded. The median community incidence was lower in high and upper-middle income countries (18.7, $n=4$ countries) than in low and lower-middle income countries (24.9, $n=6$ countries), and varied from three to 48 per 1,000 cases per year (overall median 21.8 per 1,000$)$.

Reported rotavirus burden in children aged under five years (Table 3)

Nine of the 14 countries provided data on rotavirus burden. These data were based on special studies in five countries, routine data in three, and both routine and special study data in one country.

\section{Community burden}

The median incidence of community rotavirus infection was 2.3 per 1,000 per year in low and lower-middle income countries $(n=2)$, and 0.17 per 1,000 per year $(n=3)$ in upper-middle and high income countries (overall median 0.47 per 1,000 ). The highest estimate of community rotavirus incidence was reported from Belarus. The figures from Serbia and Slovakia were low-extreme outliers. The proportion of AGE due to rotavirus infection in a community setting were $0.7 \%$ (Slovakia) and 29.4\% (Slovenia), both from routine data sources.

\section{Hospitalisation burden}

The incidences of rotavirus hospital admissions in children under the age of five years ranged from 0.13 to 3.2 per 1,000 . The median incidence of hospitalised cases was 2.5 per 1,000 per year in low and lower-middle income countries $(n=3)$ compared to 1.5 per 1,000 per year $(n=2)$ in upper-middle and high income countries (overall median 2.5 per 1,000). The median proportion of AGE hospital admissions due to rotavirus was $20.0 \%$ (between $1.7 \%$ and $28 \%, \mathrm{n}=7$ ). This proportion was lower in high and

T A B L E 2

Reported incidence of acute gastroenteritis in children aged under five years, WHO European Region (all data from routine sources except where specified)

\begin{tabular}{|c|c|c|c|c|}
\hline $\begin{array}{l}\text { Country } \\
\text { (grouped by GNI per capita) }\end{array}$ & $\begin{array}{l}\text { AGE in community } \\
\text { (cases per } 1,000 \text { per year) }\end{array}$ & Year of data collection & $\begin{array}{l}\text { AGE in hospital } \\
\text { (cases per 1,000 per year) }\end{array}$ & $\begin{array}{l}\text { Year of data collection } \\
\text { (Special study) }\end{array}$ \\
\hline \multicolumn{5}{|l|}{ Low income countries } \\
\hline Kyrgyzstan & & & 12.4 & $2004 \mathrm{~S}^{\mathrm{a}}$ \\
\hline Tajikistan ${ }^{b}$ & 48 & Not stated & & \\
\hline \multicolumn{5}{|l|}{ Uzbekistan } \\
\hline \multicolumn{5}{|c|}{ Lower-middle income countries } \\
\hline Albania & & & 782 & 2005 \\
\hline Belarus & 7 & 2005 & & \\
\hline Georgia & 19 & 2004 & & \\
\hline Rep. of Moldova & $29^{c}$ & 2005 & & \\
\hline \multicolumn{5}{|c|}{ Upper-middle income countries } \\
\hline Bulgaria & $28^{\mathrm{d}}$ & 2004 & & \\
\hline Croatia $^{a}$ & 11 & $1978-2005$ & & \\
\hline Montenegro ${ }^{a}$ & 34 & 2004 & & \\
\hline Serbia & 3 & 2004 & & \\
\hline Slovakia & 25 & 2003 & 7.3 & $1992-2005$ \\
\hline \multicolumn{5}{|l|}{ Turkey } \\
\hline \multicolumn{5}{|l|}{ High income countries } \\
\hline Slovenia & 42 & 2004 & 25.4 & 2004 \\
\hline
\end{tabular}

GNI: Gross national income; AGE: Acute gastroenteritis.

a Internal report: Epidemiology and Rotavirus Disease Burden in Kyrgyzstan 2003-2006; results of hospital-based surveillance;

Combined community and hospital figures;

Age group 0-6 years, not 0-4;

d Figure unclear in returned questionnaire - presented as a percentage. 
upper-middle income countries (median $6.5 \%, \mathrm{n}=2$ ) than in low and lower-middle income countries (median $25 \%, n=5$ ).

\section{Reported mortality and case-fatality ratios due to AGE and rotavirus in children under the age of five years}

Six countries provided information on mortality due to AGE or rotavirus disease. Croatia, Serbia, Montenegro and Slovenia reported zero mortality due to diarrhoeal disease (including rotavirus) in children under five years. Belarus reported zero mortality due to rotavirus but did not provide any data on mortality due to diarrhoeal disease. Slovakia reported a case fatality rate of 0.5 per 1,000 cases of AGE in children under five years (data from 1954 to 2005, three deaths).

\section{Serogroups}

Two of the 14 responding countries supplied data on circulating rotavirus strains (Table 4 ). Between 56 and $81 \%$ of the strains were G1-G4.

\section{Introduction of vaccine}

Kyrgyzstan, Uzbekistan, Georgia, Albania and Slovenia stated that they would include the Rotavirus vaccine in routine immunisations given EMEA approval. Belarus gave a tentatively positive answer. Countries stating that they would not be likely to introduce the vaccine were: Republic of Moldova, Serbia, Slovakia, Croatia and
Turkey. The countries were not asked about the timescale or degree of commitment to the introduction of the vaccination.

The six countries giving a "yes" or a tentatively positive answer to the question about vaccine introduction were relatively wellprepared, with four of the six having specific rotavirus surveillance systems and all six reporting the availability of one or more rotavirus diagnostic methods.

Disease burden was the most important factor influencing this decision (mean rank 2.2), followed by safety profile (mean rank 2.5), finances for new vaccines (3.9), and vaccine costs (4.0). Disease burden ranked first in all four upper-middle and highincome countries, but only in two of the eight low and lower-middle income countries. An additional influencing factor that was reported was the lack of laboratory capacity.

\section{T A B L E}

Circulating rotavirus strains reported by responding countries $(n=2)$

\begin{tabular}{|l|c|c|c|c|}
\hline Country & $\% G 1$ & $\% G 1-G 4$ & $\% P 8$ & Year(s) of data collection \\
\hline Albania & $12.5 \%$ & $56.3 \%$ & No data & 2001 \\
\hline Kyrgyzstan & $56.5 \%$ & $81.5 \%$ & $63.0 \%$ & $2004-2005$ \\
\hline
\end{tabular}

TA B L E 3

Reported burden of community and hospital rotavirus disease, with contribution of rotavirus to acute gastroenteritis in each setting ${ }^{\mathrm{a}}$

\begin{tabular}{|c|c|c|c|c|}
\hline $\begin{array}{l}\text { Countries } \\
\text { (grouped by GNI per capita) } \\
\text { Bold=EU } 25\end{array}$ & $\begin{array}{l}\text { Community incidence of } \\
\text { rotavirus in children under } \\
\text { five years } \\
\text { (per } 1,000 \text { ) }\end{array}$ & $\begin{array}{l}\text { Hospital incidence of } \\
\text { rotavirus in children under } \\
\text { five years (per 1,000) }\end{array}$ & $\begin{array}{l}\text { \% AGE caused } \\
\text { by RV in community }\end{array}$ & $\begin{array}{c}\% \text { AGE caused } \\
\text { by RV in hospital }\end{array}$ \\
\hline & \multicolumn{4}{|c|}{ (Year, Source: R=Routine data, S=Special study) } \\
\hline \multicolumn{5}{|l|}{ Low income countries } \\
\hline Kyrgyzstan ${ }^{b}$ & $\begin{array}{c}0.47 \\
(2005 \mathrm{~S})^{\mathrm{c}}\end{array}$ & $3.2^{\mathrm{d}}$ & & $\begin{array}{c}26 \% \\
(2003-2006, \mathrm{RS}) \\
\end{array}$ \\
\hline Uzbekistan ${ }^{b}$ & & & & $\begin{array}{c}25 \% \\
(2004-2005, \mathrm{~S})\end{array}$ \\
\hline \multicolumn{5}{|c|}{ Lower-middle income countries } \\
\hline Albania & & $\begin{array}{c}2.5^{\mathrm{e}} \\
(2001 \mathrm{~S})\end{array}$ & & $\begin{array}{c}20^{e} \\
(2001, \mathrm{~S})\end{array}$ \\
\hline Belarus & $\begin{array}{c}4.2^{f} \\
(2005 R)\end{array}$ & & & \\
\hline Georgia & & $\begin{array}{c}1.4^{g} \\
(1984-1986 \mathrm{~S})\end{array}$ & & $\begin{array}{c}28 \% 8 \\
(1984-6, \mathrm{~S})\end{array}$ \\
\hline Republic of Moldova & & & & $\begin{array}{c}16.3 \% \\
(1992-2004, \mathrm{~S})\end{array}$ \\
\hline \multicolumn{5}{|c|}{ Upper-middle income countries } \\
\hline Serbia & $\begin{array}{c}0.11 \\
(2004 \mathrm{R}) \\
\end{array}$ & & & \\
\hline Slovakia & $\begin{array}{c}0.17 \\
\text { (1992-ongoing, R) }\end{array}$ & $\begin{array}{c}0.13 \\
\text { (1992- ongoing, R) }\end{array}$ & $\begin{array}{c}0.66 \% \\
\text { (1992- ongoing,R) }\end{array}$ & $\begin{array}{c}1.7 \% \\
\text { (1992- ongoing,R) }\end{array}$ \\
\hline \multicolumn{5}{|l|}{ High income countries } \\
\hline Slovenia & $\begin{array}{c}12.3 \\
(2004 \mathrm{R})\end{array}$ & $\begin{array}{c}2.8 \\
(2004 \mathrm{R})\end{array}$ & $\begin{array}{c}29.4 \\
(2004 R)\end{array}$ & $\begin{array}{c}11.3 \\
(2004 \mathrm{R})\end{array}$ \\
\hline
\end{tabular}

GNI: Gross national income; AGE: Acute gastroenteritis; RV: rotavirus.

a No relevant data reported by Tajikistan, Bulgaria, Croatia, Montenegro and Turkey;

- One or more special studies listed in returned questionnaire but not traceable in PubMed;

c Possibly a hospital setting;

d Derived from AGE incidence (Table 2) and percentage of hospitalised AGE due to rotavirus;

e Role of rotaviruses in aetiology of AGE in children (university hospital of Tirana) - not traceable in Pubmed. In this study $20 \%$ of AGE admissions were due to

rotavirus, so the total AGE admissions would be 12.5 per 1,000, suggesting the survey reply in Table 2 (782 per 1,000) is incorrect;

Ages 0-6 not 0-4;

$g$ Doctoral thesis: Epidemiology of rotavirus gastroenteritis in Georgian SSR of 1990. 


\section{Gaps in knowledge}

Table 5 shows that less than one-third of the responding countries provided data on the incidence of rotavirus hospital admissions, and only half had information on the contribution of rotavirus to AGE hospital admissions. Only six countries returned data on mortality or case-fatality due to AGE or rotavirus, and of these only two reported an AGE or rotavirus mortality that was not zero.

Over a third ( 5 of 14 ) countries did not return any data on rotavirus burden. In four of the nine countries that sent some information about rotavirus burden, the data were derived from special studies only.

\section{Discussion}

This study was conducted in 2006, before WHO/Europe and its partners began to support the introduction of rotavirus surveillance in several countries of the WHO European Region (Azerbaijan, Georgia, Tajikistan and Ukraine). It describes the first review in the WHO European region of rotavirus surveillance, laboratory capacity, and willingness to introduce these newly developed and licensed vaccines. The results of the survey show, at least for the 14 countries that returned the questionnaire, that the current capacity for rotavirus surveillance and laboratory diagnosis is heterogeneous in the region. Gaps in the knowledge of rotavirus burden existed in a number of countries, although according to those countries that were able to provide data, rotavirus contributes considerably to hospital admissions due to diarrhoea.

\section{Surveillance systems}

Specific surveillance systems for rotavirus infections were present in less than one third of the surveyed countries, and in half of them the reported coverage was limited. Nevertheless, most responding countries had sufficient data from routine sources or special studies to give an estimate of the burden of rotavirus disease in the community or in hospitals, which would assist in making an informed decision regarding the potential introduction of the vaccine.

\section{Laboratory capacity}

In terms of laboratory capacity, most responding countries had access to either ELISA or latex tests for rotavirus detection. ELISA is currently the method of choice for most laboratories, being more sensitive than the latex assays [16] and more specific for clinically relevant infections than reverse transcription polymerase chain reaction (RT-PCR) which may also identify asymptomatic infections [17]. However, rotavirus diagnostic capacity was generally poor in the lower-income countries, in which - with one exception less than one quarter of the laboratories had diagnostic facilities. Whilst diagnosis is not always clinically necessary in low-income settings, its lack limits the options for monitoring rotavirus burden. A regional laboratory network for rotavirus surveillance in the WHO European Region has recently been established [18], and this should improve laboratory capacity with development of standards, frequency of testing, and analysis of circulating strains. The initial members were Denmark, Finland, France, Germany, Hungary, Italy, Netherlands, Slovenia, Spain, Sweden and the United Kingdom. Further countries may be included as the network expands [18].

TA B L E 5

Laboratory capacity and burden information, all countries responding to the survey $(n=14)$

\begin{tabular}{|c|c|c|c|c|c|}
\hline $\begin{array}{l}\text { Country } \\
\text { (Bold for EU 25) }\end{array}$ & $\begin{array}{l}\text { Percentage } \\
\text { laboratories } \\
\text { with rotavirus } \\
\text { diagnostics }\end{array}$ & $\begin{array}{l}\text { Any rotavirus } \\
\text { burden data? }\end{array}$ & $\begin{array}{l}\text { Incidence of } \\
\text { rotavirus hospital } \\
\text { admissions } \\
\text { reported? }\end{array}$ & $\begin{array}{l}\text { Rotavirus } \\
\text { contribution to } \\
\text { AGE admissions } \\
\text { reported? }\end{array}$ & Rotavirus data sources \\
\hline \multicolumn{6}{|l|}{ Low income countries } \\
\hline Tajikistan & $0 \%$ & No data & No data & No data & NA \\
\hline Kyrgyzstan & $10 \%$ & $\sqrt{ }$ & No data & $\sqrt{ }$ & Routine and special studies \\
\hline Uzbekistan & $2 \%$ & $\sqrt{ }$ & No data & $\sqrt{ }$ & Special studies \\
\hline \multicolumn{6}{|c|}{ Lower-middle income countries } \\
\hline Albania & No data & $\sqrt{ }$ & $\sqrt{ }$ & $\sqrt{ }$ & Special studies \\
\hline Belarus & $100 \%$ & $\sqrt{ }$ & No data & No data & Routine data \\
\hline Georgia & $5 \%$ & $\sqrt{ }$ & $\sqrt{ }$ & $\sqrt{ }$ & Special studies \\
\hline Republic of Moldova & $2 \%$ & $\sqrt{ }$ & No data & $\sqrt{ }$ & Special studies \\
\hline \multicolumn{6}{|c|}{ Upper-middle income countries } \\
\hline Bulgaria & No data & No data & No data & No data & NA \\
\hline Croatia & No data & No data & No data & No data & NA \\
\hline Montenegro & No data & No data & No data & No data & NA \\
\hline Serbia & No data & $\sqrt{ }$ & No data & No data & Routine data \\
\hline Slovakia & $17 \%$ & $\sqrt{ }$ & $\sqrt{ }$ & $\sqrt{ }$ & Routine data \\
\hline Turkey & No data & No data & No data & No data & NA \\
\hline \multicolumn{6}{|l|}{ High-income countries } \\
\hline Slovenia & $100 \%$ & $\sqrt{ }$ & $\sqrt{ }$ & $\sqrt{ }$ & Routine data \\
\hline $\begin{array}{l}\text { Overall percentage of } \\
\text { missing data }\end{array}$ & $\begin{array}{c}43 \% \\
(6 / 14)\end{array}$ & $\begin{array}{c}36 \% \\
(5 / 14)\end{array}$ & $\begin{array}{c}71 \% \\
(10 / 14)\end{array}$ & $\begin{array}{c}50 \% \\
(7 / 14)\end{array}$ & \\
\hline
\end{tabular}

NA: not applicable 
Participation in the eastern part of the WHO European Region, however, remains limited.

\section{Community and hospital burden}

The community incidence estimates were not significantly greater than hospital incidences and showed greater variability. The true ratio of rotavirus community cases to hospital admissions has been estimated at eight [10], suggesting that the community incidences reported here are substantially underestimated. Differences in laboratory methods and testing policies may at least partially account for underestimation of community rotavirus incidences. For these reasons, and because the vaccines are more effective against severe disease [1,2], surveillance for rotavirus hospitalisations and deaths is likely to provide more useful indicators than surveillance for all infections.

The gaps in knowledge about the burden of severe rotavirus infections were especially marked for hospitalisation data with $71 \%$ of countries not able to provide data on the incidence of hospital admissions due to rotavirus infection. However, recent developments suggest that the situation is improving: Two low-income countries, Uzbekistan and Kyrgyzstan have started hospital surveillance for rotavirus, albeit with low overall coverage. Uzbekistan has recently undertaken a cost-effectiveness study for rotavirus vaccination [19]. Azerbaijan, Georgia, Tajikistan and Ukraine initiated sentinel hospital surveillance in late 2006. WHO/Europe has developed an accessible database of hospital admission statistics for a number of countries in the WHO European region [20]. This will be useful for future comparative studies of rotavirus burden.

\section{Rotavirus mortality}

Rotavirus infection is an important cause of death in low and lower-middle income countries worldwide [9]. None of the countries in these income categories were able to provide data on deaths due to rotavirus infections. The countries that did provide data on mortality, with one exception all reported that they had not had any deaths due to $A G E$ or rotavirus.

The mortality data sent from those countries were at odds with WHO mortality data [21], which estimate that diarrhoeal disease contributes to between $0.3 \%$ (Croatia) and 6\% (Serbia) of all deaths in children under the age of five years. It is likely that the death certification data supplied by countries to WHO is not collected in the same way or by the same departments as the data supplied by the people completing our survey. Public health authorities producing epidemiological data on the burden of gastrointestinal illness, which may be used by decision-makers for vaccine programmes, should use the death certification data to validate their mortality estimates.

\section{Rotavirus strains}

Only two countries returned data on circulating strains, and the available analyses were from different years. The strain categories correspond to those found in the licensed vaccines, G1P[8] in the monovalent Rotarix ${ }^{\mathrm{TM}}$ vaccine (GSK Biologicals, Belgium), and G1-G4 and P[8] in the pentavalent RotaTeq $\AA$ vaccine (Merck\&Co. Inc, USA)

The lack of up-to-date information suggests that strain analyses are not done routinely in this part of the European region. The literature on rotavirus strains circulating in the European Union has been reviewed, including considerably more information than was gathered in the survey [22]. The predominant strain can shift rapidly, as was recently observed in Spain where the usual G1 P[8] and G4 P[8] strains found between 1997 and 2004 were found to have been supplanted by G(9) P[8] in a 2005 study [23]. Therefore countries considering the introduction of rotavirus vaccination should, at least intermittently, monitor the circulating strains. Work needs to be undertaken to extend strain identification in the Eastern part of the European region.

\section{Study limitations}

The main limitations of our study are the low response rate, the challenge of responding to hypothetical questions on vaccine introduction, and the variability of responses relating to disease burden. Although only 14 of 23 countries responded, we did obtain responses from all the low income countries and nearly half of the low-middle income countries. The reported incidences of AGE and rotavirus infections varied widely and in some cases (Slovakia, Albania) were likely to be under- or over-estimated: The Albanian estimate of 782 admissions for AGE per 1,000 per year is at odds with their quoted incidence of rotavirus admissions (2.5 per 1,000). The low estimates of rotavirus incidence in Slovakia may be due to the reported low coverage of the surveillance system, with only $1 \%$ of stool samples being tested for rotavirus.

\section{Conclusions}

In summary, our study shows that rotavirus surveillance and diagnosis capacity was heterogeneous in the responding countries in the eastern part of the WHO European Region, with significant gaps in disease data and laboratory capacity. This lack of diagnostic and routine surveillance activity need not prevent countries from making a decision, based on their own measured disease burdens, on whether to introduce rotavirus vaccine. A time-limited epidemiological or surveillance study should be sufficient and indeed is necessary to provide an estimate of current rotavirus burden to make an informed decision regarding inclusion of any vaccine. Several countries have already undertaken such studies.

For countries that decide to adopt a universal rotavirus vaccination programme, it is critical to introduce and/or maintain surveillance for rotavirus infections or their contribution to the gastroenteritis burden in order to assess the programme's impact, effectiveness and safety. Focusing on hospitalised cases and deaths may be the most cost-effective method. Surveillance will require sufficient laboratory capacity, and should also include a facility or access to a facility for monitoring circulating strains (in case of strain replacement).

The financial implications of a possible introduction of universal vaccination will be a major issue due to the cost of the vaccine. This will be of particular significance in low-income countries where the burden of severe rotavirus disease is likely to be greater than in wealthier countries. Consideration will need to be given to financing schemes supporting the introduction of rotavirus vaccine at reduced cost in these settings, as recently proposed through second stage of GAVI investment in rotavirus vaccines, in which low income countries will be potentially supported [13].

* The 23 countries were: Albania, Armenia, Azerbaijan, Belarus, Bosnia and Herzegovina, Bulgaria, Croatia, The Former Yugoslav Republic of Macedonia, Georgia, Kazakhstan, Turkey, Turkmenistan, Ukraine and Uzbekistan. 


\section{Acknowledgements:}

Many thanks go to Alex Doroshenko (HPA Centre for Infections); Charmaine Gauchi (Health division, Malta); Dorothea Matysiak-Klose und Miriam Wiese-Posselt (Robert Koch Institute, Germany).

Thanks also go to all the national counter-parts who responded to the survey:

Silvia Bino (Institute of Public Health, Albania); Vladimir Pashkovich (Republic centre of hygiene, epidemiology and public health, Belarus); Bernard Kaic (Institute of Public Health, Croatia); Ekaterina Zangaladze (National centre for disease control and medical statistics, Georgia Kalia Kasymbekova (Department of Epidemiology, Kyrgyzstan ministry of public health); Dragan Lausevic (Centre for disease control and prevention, Montenegro); Viktoria Gidirim (National centre for preventive medicine, Republic of Moldova); Danijela Simic (Institute of public health of Serbia, Serbia ); Maria Avdicova (Regional institute of public health, Slovakia); Eva Grilc, (Slovenian Institute of Public Health); Sohibnazar Turkov (Centre for immunisation, Tajikistan); Mehmat Ali Torunoglu (Primary healthcare general directorate, ministry of health, Turkey); Erkin Musabaev (Scientific research institute for virology, Uzbekistan)

\section{References}

1. Ruiz-Palacios GM, Pérez-Schael I, Velázquez FR, Abate H, Breuer T, Clemens SC, et al. Safety and efficacy of an attenuated vaccine against severe rotavirus gastroenteritis. N Engl J Med. 2006; ;354(1):11-22.

2. Vesikari T, Matson DO, Dennehy P, Van Damme P, Santosham M, Rodriguez Z, et al. Safety and efficacy of a pentavalent human-bovine (WC3) reassortant rotavirus vaccine. $N$ Engl J Med. 2006;354(1):23-33.

3. Vesikari T, Rautanen T, Von Bonsdorff CH. Rotavirus gastroenteritis in Finland: burden of disease and epidemiological features. Acta Paediatr Suppl. 1999;88(426):24-30.

4. European Medicines Agency (EMEA). European public assessment report: Rotarix. Accessed December 2007. Available from: http://www.emea.europa. eu/humandocs/Humans/EPAR/rotarix/rotarix.htm

5. European Medicines Agency (EMEA). European public assessment report: Rotateq European medicines agency website Accessed December 2007. Available from: http://www.emea.europa.eu/humandocs/Humans/EPAR/rotateq/rotateq.htm

6. New medicine: Rotarix. The Pharmaceutical journal 2006;276(7402):619. Available from: http://www.pharmj.com/pdf/_donotindex/pj_20060527_nb.pdf

7. Djuretic T, Ramsay M, Gay N, Wall P, Ryan M, Fleming D. An estimate of the proportion of diarrhoeal disease episodes seen by general practitioners attributable to rotavirus in children under 5 y of age in England and Wales. Acta Paediatr Suppl. 1999;88(426):38-41.

8. Koopmans M, Van Asperen I. Epidemiology of rotavirus infections in The Netherlands. Acta Paediatr Suppl. 1999;88(426):31-7.

9. Parashar UD, Hummelman EG, Bresee JS, Miller M.A., Glass RI. Global illness and deaths caused by rotavirus disease in children. Emerg Infect Dis. 2003;9(5):565-72.

10. Soriano-Gabarró M, Mrukowicz J, Vesikari T, Verstraeten T. Burden of rotavirus disease in European Union countries. Pediatr Infect Dis J. 2006;25(1 Suppl):S7-S11.

11. Semenza JC, Roberts L, Henderson A, Bogan J, Rubin CH. Water distribution system and diarrheal disease transmission: A case study in Uzbekistan. Am J Trop Med Hyg. 1998;59(6):941-6.

12. World Health Organization Regional office for Europe. European Health for all database. World Health Organization. Accessed 2006. Available from: http:// www.euro.who.int/hfadb

13. GAVI Alliance will finance rotavirus vaccines in world's poorest countries. Press release from the Joint meeting of the GAVI Alliance and Fund boards, November 2006. Available from: http://www.gavialliance.org/media_centre/ press_releases/2006_11_29_en_pr_berlin_rota.php

14. World Bank website. World Development Indicators Online (WDI). World Bank website 2007. Available from: http://web.worldbank.org/WBSITE/EXTERNAL/ DATASTATISTICS/ 0,,contentMDK:20398986 menuPK:64133163 page PK:64133150 $\sim$ piPK:64133175 theSitePK:239419,00.html

15. World Bank country classifications: a short history. World Bank Data and Statistics [Accessed December 2007]. Available from: http://go.worldbank. org/U9BK7IA1J0
16. Altindis M, Yavru S, Simsek A, Ozkul A, Ceri A, Koc H. Rotavirus infection in children with acute diarrhea as detected by latex agglutination, ELISA and polyacrylamide gel electrophoresis. Indian Pediatr. 2004;41(6):590-4.

17. Amar CF, East CL, Gray J, Iturriza-Gomara M, Maclure EA, McLauchlin J. Detection by PCR of eight groups of enteric pathogens in 4,627 faecal samples: reexamination of the English case-control Infectious Intestinal Disease Study (1993-1996). Eur J Clin Microbiol Infect Dis. 2007;26(5):311-23.

18. European collaborating group on rotavirus. Rotavirus Surveillance in Europe: Determining the Diversity of Co-circulating Rotavirus Strains in Consecutive Rotavirus Seasons. 2006 [unpublished report].

19. Isakbaeva ET, Musabaev E, Antil L, Rheingans R, Juraev R, Glass RI, et al. Rotavirus disease in Uzbekistan: cost-effectiveness of a new vaccine. Vaccine. 2007;25(2):373-80.

20. World Health Organization Regional Office for Europe. European hospital morbidity database. 2007. Copenhagen, Denmark. Available from: http://data. euro.who.int/hmdb/index.php

21. World Health Organization. Core Health Indicators. World Health Organization Statistical Information System 2006. Available from: http://www.who.int/ whosis/database/core/core_select.cfm

22. Desselberger U, Wolleswinkel-van den Bosch J, Mrukowicz J, Rodrigo C, Giaquinto C, Vesikari T. Rotavirus types in Europe and their significance for vaccination. Pediatr Infect Dis J. 2006;25(1 Suppl):S30-S41.

23. Sanchez-Fauquier A, Montero V, Moreno S, Sole M, Colomina J, Iturriza-Gomar $M$, et al. Human rotavirus $G 9$ and $G 3$ as major cause of diarrhea in hospitalized children, Spain. Emerg Infect Dis. 2006;12(10):1536-41.

This article was published on 21 August 2008

Citation style for this article: Williams CJ, Gray J, Pebody RG, Lobanov A. Survey of rotavirus surveillance, laboratory capacity and disease burden in the eastern part of the WHO European Region. Euro Surveill. 2008;13(34):pii=18959. Available online: http://www.eurosurveillance.org/ViewArticle. aspx?ArticleId=18959 